\title{
Positive language leads to positive wellbeing
}

\author{
Wendy Mitchell offers advice on helping patients who, like her, live with dementia
}

Wendy Mitchell

No one likes to be given bad news, and a diagnosis of dementia is devastating. How wonderful it would be though if the bad news and negative language stopped at that point.

If someone tells you day after day that you're suffering, you end up believing it. It has a negative impact on your wellbeing. The same would happen if you were told day after day that you are stupid-you end up thinking there might be something in it.

\section{Don't just tell me that l'm getting worse}

It would be so useful if clinicians, having given the diagnosis, could then use positive language to help patients think differently from that point forward. Patients have little control over their deterioration, but they do have control over their attitude. With the help of specialists and general practitioners, they could see the more positive side of a bummer of a diagnosis.

Patients often go through the process of taking the mini mental state examination test (a simple test taken at each visit to the memory clinic to assess how much less patients can remember) and are given our score, which has often gone down. How much better it would be for clinicians then to offer advice and support on how patients can develop strategies to help compensate for the part of the brain affected by deterioration. For example, if it's purely deterioration in memory, to explore all the options around useful devices- has the patient got a memory aid such as a notice board at home or a notebook? Does he or she set alarms? Many free apps, such as Mindmate, can help.

If the problem is orientation, does the patient have a clock that details not only the time of day, but also the date and whether it is am or pm.

\section{Change the way you take a history}

Ask simple, clear questions and wait for answers - don't fire questions at patients as it will simply confuse them.
It can be difficult to find the right words to answer open questions such as "What does the pain feel like?" But it is also difficult to answer multiple choice questions-for example, "Is it a dull, sharp, aching or crushing pain"? Patients might only remember the last choice given. Instead, ask: "Is it a dull pain?" and wait for the answer before asking "Is it a sharp pain?" and so on. It may feel unfamiliar and slow to doctors, but it will help.

And as memory is the worst asset of a patient with dementia, don't rely on it for information.

\section{What is minor to some might be huge for others}

Think how the current condition may impact on a patient's life. As an example, chronic foot pain is uncomfortable for most people but not urgent, because they might still be able to drive or ride a bike. For many people with dementia, driving or cycling is no longer possible, so walking is their only mode of transport. In the world of patients with dementia, walking may be the only thing they can now do and enjoy. It might, however, lead to isolation, which then leads on to further problems. Patients might not easily be able to go food shopping. If doctors consider this point they can help patients with an urgent referral for physiotherapy or other treatment, rather than a routine referral, which may entail waiting weeks for an appointment. If treatment is delayed, it could lead to other issues such as further pressure on already stretched healthcare resources.

Competing interests: I have read and understood BMJ policy on declaration of interests and declare the following: none.

Published by the BMJ Publishing Group Limited. For permission to use (where not already granted under a licence) please go to http://group.bmj.com/group/rights-licensing/ permissions 


\section{What you need to know}

If someone's memory is deteriorating, avoid negative language; offer positive strategies he or she can use to compensate Ask clear questions one at a time rather than multiple choice questions

Dementia can impact on seemingly small health problems; you may need to have a lower threshold for offering appointments or treatment

This patient describes her experience in the UK. Patients with dementia are generally referred by their general practitioner/family doctor to a memory clinic led by psychiatrists. Various memory tests, including the MMSE, may be performed first to confirm the diagnosis, and later to monitor the patient's progress 